\title{
BIBLIOGRAFIE
}

\section{WYKAZ PRAC DYPLOMOWYCH Z ANTYKU CHRZEŚCIJAŃSKIEGO UKOŃCZONYCH W NIEKTÓRYCH OŚRODKACH NAUKOWYCH W LATACH 2014-2015*}

\section{DZIAŁY TEMATYCZNE}

1. Prace ogólne

2. Historia wspólnot, instytucji, okresów historycznych, regionów

3. Historia doktryn (teologia i filozofia)

4. Hagiografia, monastycyzm, historia duchowości

5. Archeologia i historia sztuki

6. Apokryfy

7. Gnostycyzm

8. Patrystyka i średniowiecze (łacińskie i bizantyńskie)

9. Autorzy

10. Wybrane prace dyplomowe z zakresu kultury klasycznej

\section{Prace ogólne}

Czernia Ewa, Stanowisko Ojców Wschodnich wobec aborcji, Opole 2014, WT UO, prom. ks. prof. dr hab. Norbert Widok (mgr).

Kutek Krzysztof, Ks. dr hab. Wojciech Kania. Życie i działalność duszpastersko dydaktyczno - naukowa, Tarnów 2015, WTST UPJPII, prom. ks. prof. dr hab. Antoni Żurek (mgr).

Majchrzak Marcin, Religijność w czasach Juliana Apostaty, Poznań 2015, WH UAM, prom. prof. dr hab. Kazimierz Ilski (mgr).

Nowak Adam, Motyw suplikacji w tacińskiej poezji patrystycznej i jego reminiscencje w poezji polskiej, Lublin 2015, WT KUL, WSD Kielce, prom. ks. dr hab. Jarosław Marczewski (mgr).

\section{Historia wspólnot, instytucji, okresów historycznych, regionów}

Banasiak Bartłomiej, Najazdy Gotów na Cesarstwo Rzymskie w III wieku, Poznań 2015, WH UAM, prom. prof. dr hab. Jan Prostko-Prostyński (mgr).

Bartoszek Juliusz, Praktyka pokuty w kościele pierwotnym, Lublin 2014, WT KUL, prom. ks. dr hab. Piotr Szczur, prof. KUL (mgr).

Gębczyński Michał, Antiochia Syryjska w cieniu katastrof Vi VI w. Rozkwit i upadek

* W wykazie uwzględniono również niektóre prace z wcześniejszych lat, które nie były jeszcze odnotowane w „Vox Patrum”. Umieszczone w nawiasach skróty oznaczają: mgr - praca magisterska, lic. - praca licencjacka (licencjat kanoniczny), dr - praca doktorska, hab. - praca habilitacyjna. 
wielkiej metropolii antycznej, Kraków 2014, WH UJ, prom. dr hab. Stanisław Turlej (mgr).

Gutowska-Kowalczyk Agata, Wpływ kultury, historii $i$ wierzeń starożytnej Syrii na kształt wspólnoty chrześcijan z terenu Antiochii w pierwszych wiekach chrześcijaństwa, Warszawa 2014, WT UKSW, prom. dr hab. Aldona Piwko (mgr).

Kocimski Krzysztof, Prześladowanie chrześcijan w Persji IV-VI wieku, Warszawa 2013, WNHiS UKSW, prom. ks. prof. dr hab. Józef Naumowicz (mgr).

Kot Przemysław, Biskup w gminie chrześcijańskiej w okresie Ojców Apostolskich, Kraków 2014, WH UJ, prom. dr hab. Michał Stachura (mgr).

Przybylski Piotr, Konstantyn Wielki. Między religia chrześcijańska a starorzymska, Poznań 2014, WFPiK UAM, prom. prof. dr hab. Leszek Mrozewicz (mgr).

Staśkiewicz Tomasz, Świat pogański z perspektywy chrześcijan na podstawie apologetów greckich w II wieku, Poznań 2015, prom. ks. dr hab. Paweł Wygralak, prof. UAM (mgr).

Więckowski Paweł, Humanizacja systemu niewolniczego we wczesnym Cesarstwie Rzymskim (I-III w. po Chr.), Warszawa 2014, WNHiS UKSW. Obrona 19 XII 2014, prom. ks. prof. dr hab. Józef Naumowicz, recenzenci: ks. dr hab. Tadeusz Kołosowski (UKSW), dr hab. Danuta Okoń, prof. US (Szczecin).

Wilkosz Mateusz, Praktyczne wskazania dla duchownych w prawodawstwie synodów kartagińskich (381-431 r.), Poznań 2014, WT UAM, prom. ks. dr hab. Bogdan Czyżewski, prof. UAM (mgr).

Zjeżdżałka Paweł, Społeczeństwo wizygockie w IV-VIII wieku, Poznań 2015, WH UAM, prom. prof. dr hab. Jan Prostko-Prostyński (mgr).

\section{Historia doktryn (teologia i filozofia)}

Bartkowiak Izabela, Musica Mundana - koncepcja harmonii sfer od Pitagorasa do Boecjusza. Studium hermeneutyczne, Lublin 2014, WT KUL, prom. ks. dr Lucjan Dyka (mgr).

Krawiec Jakub, Zbawienie Żydów w myśli wczesnochrześcijańskiej, Kraków 2014, WT UPJPII, prom. dr hab. Dariusz Kasprzak OFMCap, prof. UPJPII (mgr).

Sękowski Piotr, Chrystologia arabska. Pierwsze syntezy wyznań pochalcedońskich, Opole 2014, WT UO, prom. ks. prof. dr hab. Norbert Widok (mgr).

\section{Hagiografia, monastycyzm, historia duchowości}

Dziewulski Jakub, Kultura kulinarna w klasztorach wczesnochrześcijańskich na podstawie wybranych regut monastycznych, Warszawa 2012, WNHiS UKSW, prom. ks. dr hab. Tadeusz Kołosowski, prof. UKSW (mgr).

Macios Zofia, Historia ośrodków monastycznych w Kapadocji na przykładzie Derinkuyu, Warszawa 2015, WT UKSW, prom. ks. dr Mirosław Mejzner (mgr).

Tkaczyk Amanda, Duchowość bizantyjska na przykładzie hymnu i ikony, Kraków 2015, WF UJ, prom. dr hab. Dariusz Brodka, prof. UJ (mgr).

Tymińska Kinga, Miejsca Święte zwiqzane z życiem $i$ działalnościa Jezusa $u$ wybranych pisarzy chrześcijańskich od IV do VIII wieku, Warszawa 2012, WNHiS UKSW, prom. ks. dr hab. Tadeusz Kołosowski, prof. UKSW (mgr).

\section{Archeologia i historia sztuki}

Godlewska Aleksandra, Watki ikonograficzne pasji $i$ zmartwychwstania $w$ sztuce 
wczesnochrześcijańskiej i bizantyńskiej do ikonoklazmu (IV-IX w.), Kraków 2014, WH UJ, prom. dr hab. Małgorzata Smorag-Różycka (mgr).

Szytuła Joanna, Mozaika $w$ absydzie kościoła pw. Świętej Pudencjany $w$ Rzymie - analiza ikonograficzna i rys historyczny, Kraków 2014, WH UJ, prom. dr hab. Małgorzata Smorąg-Różycka (mgr).

\section{Apokryfy}

Jaglińska Marta, Drugie życie apokryfu, czyli o konstrukcjach narracyjnych $i$ intencjonalności tekstów biblijno-apokryficznych we współczesności. Analiza na podstawie wybranych polskich utworów prozatorskich, Warszawa 2015, WNH UKSW, prom. dr hab. Krzysztof Koehler, prof. UKSW (mgr).

Polák Richard, Apokryfy jako świadectwo rodzqcego się Kościoła, Warszawa 2014, WT UKSW, prom. ks. dr Arnold Zawadzki (mgr).

\section{Gnostycyzm}

Buczak Kamil, Plotyn o szkodliwym wpływie gnostyków na duszę ludzką, Lublin 2015, WF KUL, prom. prof. dr hab. Agnieszka Kijewska (mgr).

\section{Patrystyka i średniowiecze (lacińskie i bizantyńskie)}

Malinowski Rajmund, Belizariusz i Narzes. Wodzowie Justyniana, Lublin 2015, WNH KUL, prom. dr hab. Piotr Kochanek, prof. KUL (mgr).

Panto Dmitriy, Relacja rozumu do autorytetu w pismach Eriugeny, Lublin 2014, WF KUL, prom. prof. dr hab. Agnieszka Kijewska (mgr).

\section{Autorzy}

\section{Ambroży}

Fedarovich Pavel, Droga doskonalenia chrześcijańskiego - nauka o cnotach na podstawie wybranych dziet świętego Ambrożego (Epistulae et De officiis ministrorum), Lublin 2015, WT KUL, prom. ks. prof. dr hab. Jerzy Pałucki (mgr).

Jędrzejczak Małgorzata, Chrześcijanin wobec dóbr materialnych wedtug wskazań „De Nabuthae” $i$,,De officiis ministrorum” św. Ambrożego, Poznań 2014, WT UAM, prom. ks. dr hab. Paweł Wygralak, prof. UAM (mgr).

Krawczyk Michał, Kapłan-formacja i postuga wświetle epistolografii św. Ambrożego $i$ św. Paulina z Noli, Lublin 2014, WT KUL. Obrona: 26 IX 2014, promotor ks. prof. dr hab. Jerzy Pałucki, recenzenci: ks. dr hab. Paweł Wygralak, prof. UAM, ks. dr hab. Piotr Turzyński (KUL) (dr).

Król Antoni, Jałmużna $w$ nauczaniu duszpasterskim św. Bazylego Wielkiego, św. Ambrożego i św. Jana Chryzostoma, Tarnów 2016, WTST UPJPII, prom. ks. prof. dr hab. Antoni Żurek (mgr).

Nadobnik Wojciech, Obowiazek w systemie pojęć Cycerona i świętego Ambrożego, Poznań 2014, WH UAM, prom. prof. dr hab. Kazimierz Ilski (mgr).

Ogar Marcin, Sapientia vitae. Madrość w życiu chrześcijanina na podstawie korespondencji i dzieł moralno-ascetycznych św. Ambrożego z Mediolanu, Lublin 2015, WT KUL. Obrona: 15 VI 2015, promotor ks. prof. dr hab. Jerzy Pałucki, recenzenci ks. dr hab. Michał Kieling, prof. UAM, bp dr hab Piotr Turzyński (KUL) (dr).

Sobiech Marcin, Rzeczywistość wiary w traktacie „De fide” $i$ epistolografii św. 
Ambrożego, Lublin 2015, WT KUL. Obrona: 26 VI 2015, promotor ks. prof. dr hab. Jerzy Pałucki, recenzenci: prof. dr hab. Jerzy Wojtczak-Szyszkowski (UW), ks. dr hab. Tadeusz Kołosowski, prof. UKSW (dr).

Wieczorek Michał, Cnota dziewictwa w nauce św. Ambrożego z Mediolanu, Opole 2014, WT UO, prom. ks. prof. dr hab. Norbert Widok (mgr).

\section{Auzoniusz}

Krynicka Tatiana, Decymus Magnus Auzoniusz w świetle własnych utworów, Pelplin 2014, WF UG. Obrona 31 I 2015, recenzenci: dr hab. Piotr Bering, prof. UAM; ks. dr hab. Stanisław Longosz, prof. KUL; dr hab. Tomasz Sapota (UŚ) (hab.).

\section{Augustyn z Hippony}

Buźniak Maciej, Problem pracy mnichów w ujęciu św. Augustyna, Warszawa 2015, WNHiS UKSW, prom. ks. prof. dr hab. Józef Naumowicz (mgr).

Domieracka Ewa, Miłość małżeńska u św. Augustyna w świetle wybranych tekstów, Poznań 2013, WT UAM, prom. prof. dr hab. Krzysztof Stachewicz (mgr).

Druszcz Przemysław, Zagadnienie zmartwychwstania i przymiotów ciała zmartwychwstałego na podstawie 13 i 22 rozdziału „,De civitate Dei” św. Augustyna, Kraków 2015, WT UPJPII, prom. dr hab. Dariusz Kasprzak OFMCap, prof. UPJPII (mgr).

Ślusarczyk Adam, Miłosierdzie w ,,Wyznaniach” świętego Augustyna, Lublin 2015, WT KUL, WSD Radom, prom.bp dr hab. Piotr Turzyński (mgr).

Tobera Paweł, Pokora w ,, Objaśnieniach do Psalmów” świętego Augustyna, Lublin 2014, WT KUL, WSD Radom, prom. ks. dr hab. Piotr Turzyński (mgr).

Żelisławski Jurand, Nauka o kapłaństwie $w$ wybranych pismach św. Augustyna, Poznań 2014, WT UAM, prom. ks. dr hab. Antoni Swoboda, prof. UAM (mgr).

\section{Bazyli Wielki}

Cabaj Marcin, Pneumatologia świętego Bazylego Wielkiego w świetle dzieła „O Duchu Świętym”, Lublin 2014, WT KUL, WSD Radom, prom. ks. dr hab. Marek Wiesław Jagodziński (mgr).

Król Antoni, Jałmużna w nauczaniu duszpasterskim św. Bazylego Wielkiego, św. Ambrożego i św. Jana Chryzostoma, Tarnów 2016, WTST UPJPII, prom. ks. prof. dr hab. Antoni Żurek (mgr).

Plonsak Liliia, Ideat świętości w świetle wybranych dziet św. Bazylego Wielkiego, Lublin 2014, WT KUL, prom. ks. dr hab. Jarosław Marczewski (mgr).

\section{Benedykt z Nursji}

Wieteska Barbara, Koncepcja pokoju w świetle życia i reguty św. Benedykta z Nursji. Studium teologicznomoralne, Warszawa 2014, WT UKSW, prom. ks. dr Jan Pieńkosz (mgr).

\section{Cyprian z Kartaginy}

Kowalik Paweł, Apologia tradycyjnej nauki o Eucharystii w „Liście 63” św. Cypriana, Opole 2014, WT UO, prom. ks. prof. dr hab. Norbert Widok (mgr).

Kwaśniewski Krzysztof, Rola biskupa we wspólnocie Kościoła w nauczaniu Św. Cypriana, Poznań 2014, WT UAM, prom. ks. dr hab. Antoni Swoboda, prof. UAM (mgr). 


\section{Cyryl Aleksandryjski}

Bernacik Jacek, Teologia Chrztu, Bierzmowania i Eucharystii w katechezach Cyryla Jerozolimskiego, Kraków 2015, WT UPJPII, prom. dr hab. Dariusz Kasprzak OFMCap, prof. UPJPII (mgr).

Nowacki Paweł, Nauczanie św. Cyryla Aleksandryjskiego o Bóstwie i człowieczeństwie Jezusa Chrystusa i jego recepcja w Magisterium Kościoła, Poznań 2015, WT UAM, prom. ks. dr hab. Michał Kieling, prof. UAM (mgr).

\section{Cyryl ze Scytopolis}

Szkudlarek Mateusz, Obraz życia monastycznego w Palestynie w pismach Cyryla ze Scytopolis, Poznań 2015, WT UAM, prom. ks. dr hab. Paweł Wygralak, prof. UAM (mgr).

\section{Dionizy Areopagita Pseudo-}

Kłos Maciej, Przebieg obrzędów Eucharystii na podstawie „Hierarchii kościelnej” Pseudo-Dionizego Areopagity, Kraków 2015, WT UPJPII, prom. ks. dr hab. Jan W. Żelazny, prof. UPJPII (mgr).

\section{Drakoncjusz}

Cichoń Natalia, Mit o porwaniu Heleny u schyłku antyku. Lektura porównawcza epyllionów Drakoncjusza i Kolluthusa, Kraków 2014, WF UJ, prom. dr hab. Antoni Bobrowski (mgr).

\section{Dydym Ślepy}

Kaoka Krzysztof, Aretologia Dydyma Aleksandryjskiego, Lublin 2014, WT KUL. Obrona 26 IX 2014, promotor ks. prof. dr hab. Mariusz Szram, recenzenci: ks. dr hab. Bogdan Czyżewski, prof. UAM, ks. dr hab. Piotr Szczur, prof. KUL (dr).

\section{Ewagriusz z Pontu}

Kałdan Jarosław, Problemy życia duchowego w nauce ascetycznej Ewagriusza z Pontu, Poznań 2015, WT UAM, prom. ks. dr hab. Antoni Swoboda, prof. UAM (mgr).

Salach Paweł, Relacja mistrz-uczeń w pismach ascetycznych Ewagriusza z Pontu, Warszawa 2015, WT UKSW, prom. ks. prof. dr hab. Bogumił Gacka (mgr).

Zawada Paweł, Człowiek wobec działania złego ducha w życiu i pismach Ewagriusza $z$ Pontu, Lublin 2015, WT KUL, MSD Lublin, prom. ks. dr hab. Jarosław Popławski, prof. KUL (mgr).

\section{Filip Prezbiter}

Jóźwiak Magdalena, ,, Komentarz do historii Hioba” Filipa Prezbitera, Wrocław 2013, Wydział Filologiczny, Instytut Studiów Klasycznych, Śródziemnomorskich i Orientalnych UWr. Obrona 13 V 2014, promotor główny: prof. dr hab. Gościwit Malinowski, promotor pomocniczy: dr Krzysztof Morta, recenzenci: ks. prof. dr hab. Mariusz Rosik (PWT Wrocław), ks. dr hab. Michał Kieling, prof. UAM (Poznań) (dr).

\section{Gelazy I, papież}

Roszak Piotr, Walka z pogańskim kultem luperkaliów w liście „,Przeciw Andromachowi” Gelazego I, Katowice 2015, WT UŚ, prom.ks. dr hab. Andrzej Uciecha (mgr). 


\section{Grzegorz Wielki}

Norek Mateusz, Ideał duchownego i mnicha w świetle „Dialogów” Grzegorza Wielkiego, Tarnów 2016, prom. ks. prof. dr hab. Antoni Żurek (mgr).

Pawlak Adam, Obrazy świętości i ich znaczenie pedagogiczne w ,Dialogach” św. Grzegorza Wielkiego, Warszawa 2014, WT UKSW, prom. ks. dr Janusz Lewandowicz (mgr).

Sokołowski Radosław, Droga doskonalenia chrześcijańskiego w świetle „,XL Homiliarum in Evangelia” świętego Grzegorza Wielkiego, Lublin 2014, WT KUL, MSD Lublin, prom. ks. prof. dr hab. Franciszek Drączkowski (mgr).

Stróżewski Mateusz, Posługa pasterska biskupów w interpretacji św. Grzegorza Wielkiego na podstawie „Listów”, Poznań 2014, WT UAM, prom. ks. dr hab. Bogdan Czyżewski, prof. UAM (mgr).

\section{Grzegorz z Nazjanzu}

Grzywocz Justyna, Miłość w pismach św. Grzegorza z Nazjanzu, Opole 2015, WT UO, prom. ks. prof. dr hab. Norbert Widok (mgr).

\section{Grzegorz z Tours}

Choda Kamil, Religia w „Historiach” Grzegorza z Tours, Kraków 2014, WF UJ, prom. dr hab. Dariusz Brodka, prof. UJ (mgr).

Kornobis Oktawiusz, Analiza starć frankijsko-rzymskich w świetle Grzegorza z Tours, Kraków 2014, WF UJ, prom. dr hab. Dariusz Brodka, prof. UJ (mgr).

Szczotka Anna, Marcin z Tours jako święty i narodowy patron Galii w świetle pism sulpicjusza Sewera i Grzegorza z Tours, Warszawa 2011, WNHiS UKSW, prom. ks. dr hab. Tadeusz Kołosowski, prof. UKSW (mgr).

\section{Hieronim}

Banasiak Paweł, Wkład św. Hieronima w kształtowanie kultury europejskiej, Warszawa 2014, WNHiS UKSW. Obrona 24 XI 2014, promotor: ks. dr hab. Tadeusz Kołosowski, prof. UKSW, recenzenci: ks. prof. dr hab. Jerzy Pałucki (KUL), ks. dr hab. Leszek Misiarczyk, prof. UKSW (dr).

\section{Hilary z Poitiers}

Kostecka Zuzanna, Listy Hilarego z Poitiers do cesarza Konstancjusza, Kraków 2014, WH UJ, prom. dr hab. Michał Stachura (mgr).

\section{Hipolit}

Kubaszewski Krzysztof, Obrazy Chrystusa i Kościoła $w$ dziełach egzegetycznych św. Hilarego z Poitiers, Poznań 2014, WT UAM, prom. ks. dr hab. Bogdan Czyżewski, prof. UAM (mgr).

\section{Jan Chryzostom}

Król Antoni, Jałmużna w nauczaniu duszpasterskim św. Bazylego Wielkiego, św. Ambrożego i św. Jana Chryzostoma, Tarnów 2016, WTST UPJPII, prom. ks. prof. dr hab. Antoni Żurek (mgr). 
Nazarok Svitlana, Kapłan jako pasterz w świetle wybranych dzieł św. Jana Chryzostoma, Lublin 2015, WT KUL, prom. ks. dr hab. Jarosław Marczewski (mgr).

Nowakowski Radosław, Praktyczne wskazania do naśladowania Chrystusa w „Homiliach na Ewangelię wedtug św. Mateusza" św. Jana Chryzostoma, Poznań 2014, WT UAM, prom. ks. dr hab. Bogdan Czyżewski, prof. UAM (mgr).

Rusiecka Jowita, Konfrontacja chrześcijaństwa z judaizmem i pogaństwem na podstawie mów apologijnych św. Jana Chryzostoma, Warszawa 2014, WT UKSW, prom. ks. prof. dr hab. Marek Skierkowski (mgr).

Zaborowicz Marcin, Liturgiczno-teologiczna interpretacja „Świętej i Boskiej Liturgii” św. Jana Chryzostoma, Poznań 2014, WT UAM, prom. ks. dr hab. Bogdan Czyżewski, prof. UAM (mgr).

\section{Jan Damasceński}

Perłowski Marcin, Polemika Jana Damasceńskiego z nestorianizmem, Warszawa 2012, WNHiS UKSW, prom. ks. prof. dr hab. Józef Naumowicz (mgr).

\section{Jan Kasjan}

Rudzinskyy Viaczeslaw OSB, Źródła autorytetu mnicha egipskiego w „Rozmowach z Ojcami” Jana Kasjana, Kraków 2014, WT UPJPII, prom. ks. dr hab. Jan W. Żelazny, prof. UPJPII (mgr).

Swat Sancjusz Krzysztof OFM, Demonologia w świetle „, Collationes Patrum” Jana Kasjana, Kraków 2014, WT UPJPII, prom. dr Roland Marcin Pancerz OFM (mgr).

\section{Jordanes}

Wilk Małgorzata, Obraz barbarzyńców w historiografii rzymskiej (Tacyt, Ammian Marcellin, Jordanes), Kraków 2014, WF UJ, prom. dr hab. Dariusz Brodka, prof. UJ (mgr).

\section{Justyn}

Berus Krzysztof, Zmartwychwstanie ciał w pismach św. Justyna i Pseudo-Justyna, Poznań 2014, WT UAM, prom. ks. prof. dr hab. Bogdan Częsz (mgr).

Olszowski Karol OSPPE, Rola prawdy w 1 i 2 Apologii Justyna męczennika oraz w ,,Wychowawcy” Klemensa Aleksandryjskiego. Studium porównawcze, Kraków 2015, WT UPJPII, prom. ks. dr hab. Jan W. Żelazny, prof. UPJPII (mgr).

\section{Klemens Aleksandryjski}

Kozioł Mirosław, Ideał przyjaźni według Klemensa Aleksandryjskiego, Lublin 2015, WT KUL, promotor ks. prof. dr hab. Jerzy Pałucki (mgr).

Olszowski Karol OSPPE, Rola prawdy w 1 i 2 Apologii Justyna męczennika oraz $w$,,Wychowawcy” Klemensa Aleksandryjskiego. Studium porównawcze, Kraków 2015, WT UPJPII, prom. ks. dr hab. Jan W. Żelazny, prof. UPJPII (mgr).

Wilczyński Krystian, Chrystus pośrednikiem w widzeniu kontemplacyjnym w ujęciu Klemensa Aleksandryjskiego, Warszawa 2015, WT UKSW. Obrona 16 X 2015, promotor ks. dr hab. Józef Grzywaczewski, prof. UKSW, recenzenci: ks. prof. dr hab. Jerzy Lewandowski (UKSW), ks. dr hab. Bogdan Czyżewski, prof. UAM (Poznań) (dr). 


\section{Koryppus Flawiusz Kreskoniusz}

Kołoczek Bartosz, Motywy pogańskie i chrześcijańskie w twórczości Flawiusza Kreskoniusza Koryppusa, Kraków 2015, WF UJ, prom. dr hab. Dariusz Brodka, prof. UJ (mgr).

\section{Marcin z Bragi}

Szymon Jakub, Problem herezji i batwochwalstwa w Galicji VI wieku na podstawie pism Marcina z Bragi, Katowice 2014, WT UŚ, prom.ks. dr hab. Andrzej Uciecha (mgr).

\section{Metody z Olimpu}

Szeptyńska Monika, Porównanie „Dialogu o miłości” Plutarcha i „Uczty X Dziewic" Metodego z Olimpu z perspektywy socjolingwistycznej w aspekcie tematyki erotycznej, Kraków 2015, WF UJ, prom. dr hab. Joanna Janik (mgr).

\section{Optat z Milewy}

Grochoła Mihał, Optat z Milewy w polemice z donatyzmem. Studium na podstawie „, Traktatu przeciw donatystom”, Opole 2014, WT UO, prom. ks. prof. dr hab. Norbert Widok (mgr).

\section{Orygenes}

Gadomski Piotr, Demonologia Orygenesa a „Contra Celsum”, Warszawa 2015, WT UKSW, prom. ks dr hab. Leszek Misiarczyk, prof. UKSW (mgr).

Kowalska Marta, Chrześcijaństwo jako „filozofia”. Studium historyczno-literackie pism Orygenesa (185-254), Warszawa 2015, WNHiS UKSW. Obrona 26 I 2015, prom. ks. dr hab. Leszek Misiarczyk, prof. UKSW, recenzenci: ks. prof. dr hab. Józef Naumowicz (UKSW), prof. dr hab. Jerzy Wojtczak-Szyszkowski (UW).

\section{Paulin z Noli}

Krawczyk Michał, Kaptan-formacja i postuga w świetle epistolografii św. Ambrożego $i s$ s. Paulina $z$ Noli, Lublin 2014, WT KUL. Obrona: 16 IX 2014, promotor ks. prof. dr hab. Jerzy Pałucki, recenzenci: ks. dr hab. Paweł Wygralak, prof. UAM, ks. dr hab. Piotr Turzyński (dr).

\section{Pawel Diakon}

Jegorow Adam, W ogniu strzat, w cieniu pytań - listy poetyckie Pawta Diakona. Studium przypadku, Kraków 2014, WF UJ, prom. dr hab. Anna Wasyl (mgr).

\section{Prokopiusz z Cezarei}

Majchrzak Marcin, Wizerunek dworu Justyniana wedtug ,,Historii wojen” Prokopiusza z Cezarei, Poznań 2015, WH UAM, prom. prof. dr hab. Kazimierz Ilski (mgr).

Voelkel Małgorzata, „Historia sekretna” Prokopiusza z Cezarei. Bhyskotliwa inwektywa czy zręczne wykorzystanie antycznych motywów do przedstawienia głównych postaci dzieła, Kraków 2014, WF UJ, prom. dr hab. Dariusz Brodka, prof. UJ (mgr).

\section{Reguta Mistrza}

Woźniak Damian, Organizacja życia w klasztorze na podstawie „Reguty Mistrza”, Poznań 2014, WT UAM, prom. ks. dr hab. Bogdan Czyżewski, prof. UAM (mgr). 
Sokrates Scholastyk

Jankowski Krzysztof, Sakralizacja władzy w narracji Sokratesa Scholastyka i Sozomenosa, Poznań 2014, WH UAM, prom. prof. dr hab. Kazimierz Ilski (mgr).

\section{Sozomen Hermiasz}

Jankowski Krzysztof, Sakralizacja władzy w narracji Sokratesa Scholastyka i Sozomenosa, Poznań 2014, WH UAM, prom. prof. dr hab. Kazimierz Ilski (mgr).

\section{Sulpicjusz Sewer}

Szczotka Anna, Marcin z Tours jako święty i narodowy patron Galii w świetle pism sulpicjusza Sewera i Grzegorza z Tours, Warszawa 2011, WNHiS UKSW, prom. ks. dr hab. Tadeusz Kołosowski, prof. UKSW (mgr).

\section{Teodoret z Cyru}

Przybylski Michał, Bóg wobec świata i człowieka w ujęciu Teodoreta z Cyru, Poznań 2014, WT UAM, prom. ks. dr hab. Antoni Swoboda, prof. UAM (mgr).

\section{Tertulian}

Bartnik Aneta, Matżeństwo w myśli Tertuliana. Ewolucja pogladów w okresie przedmontanistycznym i montanistycznym, Lublin 2015, WT KUL. Obrona 30 IX 2015, promotor ks. dr hab. Piotr Szczur, prof. KUL, recenzenci: prof. dr hab. Jerzy Wojtczak-Szyszkowski (UW), ks. prof. dr hab. Jerzy Pałucki (KUL) (dr).

Kubiszewska-Krasowska Elżbieta, Męczeństwo $w$ świetle wybranych pism Tertuliana, Warszawa 2011, WNHiS UKSW, prom. ks. dr hab. Tadeusz Kołosowski, prof. UKSW (mgr).

Łesyk Lesław, Tertulian wobec kwestii społecznych północnej Afryki. Studium pism parenetycznych, Lublin 2014, WT KUL. Obrona: 16 IX 2014, promotor: ks. prof. dr hab. Jerzy Pałucki, recenzenci: ks. dr hab. Michał Kieling, prof. UAM, ks. prof. dr hab. Mariusz Szam (KUL) (dr).

\section{Zosimos}

Dziekan Kacper, Wizerunek i recepcja barbarzyńców w „Nowej historii” Zosimosa, Poznań 2014, WH UAM, prom. prof. dr hab. Kazimierz Ilski (mgr).

\section{Wybrane prace dyplomowe z zakresu kultury klasycznej}

Adamczyk Anna, Asklepiejony jako ośrodki kultowe i lecznicze w świetle wybranych źródet greckich, Warszawa 2015, WNHiS UKSW, prom. ks. prof. dr hab. Józef Naumowicz (mgr).

Banowska Anita, Dzieje malarstwa antycznego wg „Historii naturalnej” Pliniusza, Warszawa 2014, WNHiS UKSW, prom. ks. prof. dr hab. Józef Naumowicz (mgr).

Chmielewski Tomasz, Idea zejścia do świata podziemnego $w$ literaturze antycznej. Orfeusz, Odyseusz, Eneasz, Lublin 2014, WNH KUL, prom. dr hab. Piotr Kochanek, prof. KUL (mgr).

Dąbrowski Oskar, Armia rzymska $w$ okresie wojen galijskich za Juliusza Cezara, Warszawa 2015, WNHiS UKSW, prom. ks. prof. dr hab. Józef Naumowicz (mgr). Grochowska Milena, Egipski mit ozyriacki w interpretacji Herodota i Plutarcha, Warszawa 2015, WNHiS UKSW, prom. ks. prof. dr hab. Józef Naumowicz (mgr). 
Jurkowski Jakub, Religijno-filozoficzne motywy w konsolacjach Lucjusza Anneusza Seneki, Warszawa 2015, WNH UKSW, prom. prof. dr hab. Kazimierz Pawłowski (mgr).

Malinowska Magdalena, Dzieje i rola Akropolu ateńskiego w świetle wybranych źródet greckich, Warszawa 2015, WNHiS UKSW, prom. ks. prof. dr hab. Józef Naumowicz (mgr).

Staszczuk Patryk, Helladocentryzm w greckiej literaturze antycznej, Lublin 2014, WNH KUL, prom. dr hab. Piotr Kochanek, prof. KUL (mgr).

Szcześniak Anita, Życie codzienne w pałacach Palatynu, Lublin 2015, WNH KUL, prom. dr hab. Piotr Kochanek, prof. KUL (mgr).

Wolski Patryk, Miasta portowe antycznej Sycylii, Lublin 2014, WNH KUL, prom. dr hab. Piotr Kochanek, prof. KUL (mgr).

Wiśniewska Anna, Kleopatra w świetle źródet antycznych, Lublin 2014, WNH KUL, prom. dr hab. Piotr Kochanek, prof. KUL (mgr). 